\title{
Reflexões sobre ética e
}

ciência: ensaio no contexto de

pandemia Covid-191

\section{- Reflections on ethics and science: essay in the context of the Covid-19 pandemic}

\section{Paulo César Carbonari²}

\begin{abstract}
En cuanto a la Ciencia, que iba a dar solución a todos los problemas del cielo y de la tierra, había servido para facilitar la concentración estatal y mientras por un lado la crisis epistemológica atenuaba su arrogancia, por el otro se mostraba al servicio de la destrucción y de la muerte. $Y$ así aprendimos brutalmente una verdade que debíamos haber previsto, dada la esencia amoral del conocimiento científico: que la ciencia no es por sí misma garantía de nada, porque a sus realizaciones les son ajenas las preocupaciones éticas
\end{abstract}

Ernesto Sábato, Hombres y Engranajes (1951)

Resumo: Este ensaio apresenta reflexões para tematizar uma certa compreensão de ciência e de ética. O faz recuperando elementos críticos tanto de uma quanto da outra e, particularmente da relação entre elas. As preocupações se situam no contexto dos processos de enfrentamento da pandemia Covid-19. Situa-se numa posição crítica tanto às posições anticientíficas e também aquelas que são adesistas a uma certa forma de entender a ciência como absoluta. Procura escapar do dilema que separa falsamente o debate entre "negacionismo anticientífico" e "cientificismo primário". Além dos aspectos contextuais, busca apresentar alternativas. Em tom ensaístico, faz uma crítica ao conceito de ciência tradicional, apresenta um conceito alternativo de ciência, discute critica-

11 Texto originalmente preparado para a intervenção em "Diálogos Direitos Humanos em Travessia" promovidos pela Comissão de Direitos Humanos de Passo Fundo (CDHPF) e realizado no dia 11/04/2020, às 9h, pelo Meet Google. Primeira versão publicada em 02/05/2020 em www.neipies.com/etica-e-ciencia-elementos-para-subsidiar-reflexoes/. Versão audiovisual em https://youtu.be/tdE8h5YT_gI. Esta versão é atualizada e complementada.

22 Doutor em Filosofia (Unisinos). Membro da CDHPF e do Movimento Nacional de Direitos Humanos (MNDH). 
mente ideia de progresso, de procedimentos, entre outros aspectos. Defende a proposta de uma nova ciência e de uma nova ética. O pano de fundo é explicitado pela apresentação da proposta de compreensão de direitos humanos em travessia como parte deste debate entre ética é ciência.

Palavras-chave: Ciência. Ética. Covid-19. Direitos humanos.

\begin{abstract}
This essay presents reflections to thematize a certain understanding of science and ethics. It does this by recovering critical elements from both the one and the other, and particularly the relationship between them. The concerns are in the context of the processes of coping with the Covid-19 pandemic. It is in a critical position both to anti-scientific positions and also to those who are adherents to a certain way of understanding science as absolute. It seeks to escape the dilemma that falsely separates the debate between "anti-scientific denialism" and "primary scientism". In addition to the contextual aspects, it seeks to present alternatives. In an essayistic tone, criticizes the concept of traditional science, presents an alternative concept of science, discusses critically the idea of progress, of procedures, among other aspects. He defends the proposal of a new science and a new ethics. The background is made explicit by the presentation of the proposed understanding of human rights in crossing as part of this debate between ethics and science.
\end{abstract}

Keywords: Science. Ethic. Covid-19. Human rights.

\title{
Introdução
}

A relação entre ética e ciência retorna com ênfase no contexto da Covid-19. Isto tanto no debate acadêmico quanto nos meios sociais e políticos. No segundo, digladiam-se o positivismo crasso e o fundamentalismo religioso apegado a crendices. No acadêmico, parece voltar o naturalismo ${ }^{3}$ e o cientificismo, de um lado; e, de outro, o eticismo precário, in extremis.

As implicações do debate levam, entre outras, à defesa de que a ética fique em quarentena para que a ciência possa agir de modo livre: afinal, se a ética só consegue chegar depois, porque meter-se agora, no meio do caminho? Outros entendem que há uma ética, ainda quando dela se abstém de tratar. E, quando a carga do moralismo fundamentalista se exacerba, o que se vê é a negação do mais elementar da ciência. Há também o debate bioético

3 Importante retomar a posição do filósofo Markus Gabriel. Ver, entre outras, a entrevista para IHU On Line de 13/07/2020, na qual sugere um "novo iluminismo" (um novo realismo) e faz uma crítica contundente ao naturalismo 
no sentido estrito que diz respeito aos parâmetros éticos para a investigação e para os atos dos profissionais de saúde no contexto da pandemia.

No fundo está a questão de retomar um certo conceito/concepção de ciência e pensar o que significa a tecnologia e sua aplicação aos processos de saúde/doença, parâmetros e procedimentos de ação, orientações éticas e questões de direitos humanos. Tentaremos levar adiante alguns aspectos deste debate nos limites do possível e de modo ensaístico.

\section{O que vai pela cabeça...}

Pesquisa ${ }^{4}$ feita com 140 mil pessoas de 144 países, divulgada pela revista Science, mostrou que 35\% dos brasileiros desconfiam da ciência (65\% confiam) e que um em cada quatro acredita que a produção científica não contribui para o país. No mundo, $72 \%$ das pessoas acreditam nos cientistas. Quase metade dos/as brasileiros/as afirmaram que "a ciência discorda da minha religião" e, desses, 75\% disseram que "quando ciência e religião discordam, escolho a religião". Apenas 13\% dos/as brasileiros/as entrevistados/as afirmaram ter "muita confiança" na produção científica. Entre as 144 nações, o Brasil fica em $111^{\circ}$ lugar dos que têm "muita confiança" na produção científica. Tomando em conta dados do mundo todo, no caso da saúde, a pesquisa revela uma questão forte: $73 \%$ das pessoas confiam mais em um médico ou enfermeiro do que qualquer outra fonte de aconselhamento sobre saúde - 0 que mostra haver pouco espaço para o "Dr. Google", ainda que ultimamente parece ter crescido o "Dr. Whatsapp". O estudo mostra também que as pessoas com menor renda familiar têm menos confiança nos hospitais e nos sistemas de saúde. Sobre a confiança nas vacinas: $79 \%$ das pessoas concordam que as vacinas são seguras e $84 \%$ concordam que são eficazes.

\section{Uma ideia arcaica de ciência}

Autoridades de saúde brasileiras em entrevistas ou nos pronunciamentos 5 sobre a Covid-19 têm posições em coincidência com a compreensão

4 Trata-se de “Wellcome Global Monitor 2018”. Dados colhidos da matéria de O Globo: “Um terço dos brasileiros desconfia da ciência”, publicada em 21/08/2019 Algumas ilustrações: "O duro recado da comunidade científica ao ministro da saúde”, Veja, 30/04/2020; "Mandetta diz que Bolsonaro 'exonerou a ciência’ ao demiti-lo". G1 Globo, 20/05/2020; "Nem o pior ministro da Saúde fez o que Exército está fazendo, desmontando a engrenagem do SUS”, El País, 25/06/2020; "Na pandemia, ciência e pesquisa são negligenciadas na agenda de Bolsonaro", Metrópoles, 07/06/2020.

5 Algumas ilustrações: "O duro recado da comunidade científica ao ministro da saúde”, Veja, 30/04/2020; "Mandetta diz que Bolsonaro 'exonerou a ciência' ao demiti-lo". G1 Globo, 20/05/2020; "Nem o pior ministro da Saúde fez o que Exército está fazendo, desmontando a engrenagem do SUS", El País, 25/06/2020; "Na pandemia, ciência e pesquisa são negligenciadas na agenda de Bolsonaro", Metrópoles, 07/06/2020. 
média de ciência, aquela que ainda considera meras curiosidades o que está no âmbito da física da relatividade ou da quântica e se apega ao conceito de ciência setecentista - isso quando chega a tanto. Expressam a ideia de que a ciência fornece a explicação das leis de funcionamento da natureza para que se possa, conhecendo-as, produzir mecanismos para subjugá-la. Junto com esta noção está a percepção de que a ciência produz certezas e de que estas certezas, por coincidirem com as leis da natureza, são imutáveis, eternas, absolutas. Ora, se a ciência não for capaz de produzir este "consenso", deixa de fazer sentido e facilmente se substituirá sua importância por aquilo que pode oferecer algum consolo seguro (alguns tipos de religião). Há uma certa "fetichização" da ciência. ${ }^{6}$

Mas, já faz algum tempo que o que menos há na comunidade científica é "consenso" ou mesmo "maioria". Ainda que "Uma breve história do tempo" (2000), de Stephen Howking, tenha sido lido por milhões de pessoas no mundo todo (vendeu 9 milhões de exemplares em 2002) e também no Brasil, parece que sua leitura não surtiu efeito - ou tenha resultado em efeito contrário, particularmente por parte dos "fundamentalistas terraplanistas" e "negacionistas".

Aliás, ironicamente, em se tratando da Covid-19, até o momento a maior certeza "científica" propalada como recurso para enfrentá-la é o isolamento ou distanciamento social. É a mais antiga prática da humanidade na história da "ciência", inclusive anterior a toda ciência em sentido estrito, uma prática que é mais própria do "bom senso", ainda que hoje em dia se tenha invocado sua natureza científica, talvez porque o que esteja bastante mal distribuído, contrariando a Descartes, seja exatamente o"bom senso"! O consolo científico venha da ideia de que "logo logo, os cientistas descobrirão uma vacina", o que é uma promessa bastante promissora, ainda que para sua efetivação vários protocolos próprios precisem ser efetivamente respeitados para que a solução não venha a se revelar ainda mais problema.

\section{E... incerteza...}

A expectativa de pensar e conviver com uma concepção de ciência

6 Importante revisitar a análise do "paradigma dominante" sobre a ciência moderna feita por Boaventura de Sousa Santos (2007): "[...] a nova racionalidade científica [moderna] é também um modelo totalitário, na medida em que nega o carácter racional a todas as formas de conhecimento que se não pautarem pelos seus princípios epistemológicos e pelas regras metodológicas" (2007, p. 61). Ele mostra largamente a crise deste paradigma e também do "paradigma emergente"

7 Ver várias notícias a respeito: “Brasil entra em parceria para produção de vacina contra Covid-19”, MS, 27/06/2020 e é "É possível, não certo, que vacina contra Covid-19 esteja disponível neste ano", diz desenvolvedora de Oxford. G1 Globo, 21/07/2020. 
não prepotente parece ficar para traz no afã de "salvar vidas". O que a quântica mostrou é que não há certeza na ciência e que sua melhor contribuição é sugerir hipóteses explicativas que são razoáveis para dar conta da realidade, mas que nunca são certezas e menos ainda absolutas. Elas são aquelas que melhor sugerem responder aos problemas levantados. A medicina, aliás, é uma das ciências que mais sabe disso, ainda que nos últimos tempos se tenha visto uma busca desenfreada por "apoios" para diagnóstico e resolutividade, nada desprezíveis, nem por isso, absolutos.

O prêmio Nobel de química de 1977, llya Prigogine (1996), defende exatamente o "princípio da incerteza" na ciência: a ideia da instabilidade está no centro da ciência moderna, segundo ele. Foi outro Nobel (de Física, de 1932), Werner Heisemberg, que enunciou, em 1927, o "Princípio da Incerteza ou da Indeterminação", segundo o qual é impossível medir simultaneamente e com precisão absoluta a posição e a velocidade de uma partícula ${ }^{8}$. Num momento de pandemia parece ser muito difícil aceitar esta possibilidade de ciência, ainda que seja certamente a que melhor poderia responder aos desafios postos pela pandemia. Posições absolutistas fazem mal à saúde tanto quanto vírus e outros agentes que atacam a saúde.

\section{A ciência a serviço do progresso... e da morte}

A ciência moderna nasceu, cresceu e se espalhou casada com a noção de progresso. ${ }^{9}$ Ambas e juntas deram guarida ao desenvolvimento do capitalismo e também do socialismo real. E... parece estar muito bem casada com o comunismo chinês atual, inclusive.

A ideia básica é que o domínio da natureza pela ciência e a sua aplicação pela técnica permitem que se afastem os mitos ${ }^{10}$ e se possa progredir para dias melhores. O fato é que, ainda que tenham havido avanços significativos, o que temos visto junto com eles é o agravamento da destruição dos recursos naturais e a exclusão da maior parte da humanidade dos benefícios do "progresso".

Na prática, o progresso tem significado muito de regressão, como, aliás, denunciam filósofos da Escola de Frankfurt, particularmente W. Benjamin, em "Sobre o conceito de história", de 1940 (2005), ainda antes da guerra, mas

8 Trata-se do artigo "Sobre o conteúdo descritivo da cinemática e da mecânica teórica quântica" (1927). Para uma exposição do princípio ver "The uncertainty principle”. In: Standford Encyclopedia of Philosophy. Disponível em: https:/plato.stanford.edu/entries/qt-uncertainty/. Em português, entre outras ver HEISENBERG, 1980.

9 Publicamos em nossa conta no Facebook com o título "Momento para parar: breves reflexões (anti)progresso". Disponível em: www.facebook.com/paulocesar.carbonari/posts/3246059255404898. Acesso em: 9 abr. 2020.

10 Francis Bacon foi enfático nesta percepção ao mapear os "ídola" (da tribo, da caverna, do foro e do teatro), em "Novum Organum" (1973). 
também Adorno e Horkheimer depois dela, em "Dialética do Esclarecimento", de 1947 (1991): o ângelus novus que o diga...

A história está farta de exemplos de uso da ciência e da tecnologia como recursos para promover a morte. $\mathrm{O}$ que produzido no contexto do totalitarismo nazista, quando milhões foram mortos com a mais sofisticada aplicação da ciência e da tecnologia (Ziklon B é fruto da pesquisa apurada para matar com o menor custo econômico e de sofrimento), é bom exemplo ruim. Há exemplos também nas supostas sociedades comunistas. Em ambos os casos há pesquisas científicas que nunca foram contestadas, muito pelo contrário, têm sido usadas largamente como base para o "avanço científico" que se lhe seguiu. Mas isso não é obra somente dos estados totalitários: vide o que se tem feito na África em pesquisas para combater HIV/Aids e tantas outras doenças por democracias nos últimos anos. Há uma necrociência ${ }^{11}$ que é tão poderosa e que não se dissocia da biociência... aliás, ambas se beneficiam mutuamente. Objetivamente: o positivismo mata!

O desafio 12 é parar a "locomotiva necrófila" do capitalismo predatório da vida em todas as suas manifestações. Superar estas perspectivas é o desejo de quem já não quer que a margem a que se venha a chegar seja nada mais do que "mais do mesmo". Toda esta vivência haverá de se transformar em profunda experiência, bem no sentido benjaminiano. Vamos parar o capitalismo necrófilo para poder cuidar e preservar a vida.

\section{Procedimentos discutíveis}

A ideia de que frameworks seriam suficientes para dar conta da objetividade e, dessa forma, da impossibilidade de os aspectos ideológicos e éticos entrarem no laboratório da pesquisa científica, tem se mostrado insuficiente. Os melhores protocolos procedimentais dificilmente se propõem a discutir a questão de fundo. Cometem um erro lógico básico: dão por pressuposto o que efetivamente precisa ser demonstrado. Ou seja, não se ocupam das condições e dos condicionantes vitais que constituem objetivamente (não subjetivamente) a pesquisa e os procedimentos científicos.

Não basta garantir a boa informação, que esta informação seja transparente, que haja consentimento livre e desimpedido, para que seres humanos participem em escala das pesquisas científicas. É preciso muito mais. É preciso, por exemplo, definir a medida da participação de financiadores po-

11 Achille Mbembe faz uma crítica consistente a tudo isso em "Crítica da Razão Negra” (2018).

12 Ver "Momento para parar", publicado na conta Facebook do autor https://m.facebook.com/story.php?story_fbid= 3246059255404898\&id=100000025676485, em 09/04/2020 e também publicado no site do MNDH Brasil: https:// mndhbrasil.org/momento-para-parar-breves-reflexoes-anti-progresso/ 
derosos a fim de saber se não são determinantes do direcionamento, inclusive dos protocolos, na execução das pesquisas em ciência. Além disso, até que ponto uma "patente" ou sua existência não se constituem na única meta para determinar o empenho na investigação (todo o esforço "colaborativo" pode resultar, no final, no registro por quem pode fazê-lo de modo "mais fácil" - será que mais para um europeu ou um norte-americano ou para um/a brasileiro/a ou um/a africano/a).

Está em construção uma tese "científica", nos padrões da certeza absoluta não passível de questionamentos reflexivos para "descrever as leis da natureza", de que o isolamento social ou distanciamento social é científico. Qualquer outra forma de tratar o modo de lidar com os seres humanos em termos biopolíticos neste momento seria anticientífico. Mas, ainda que necessária, não pode ser tida por uma verdade absoluta, nem mesmo uma lei da natureza. Até porque, esta proposta não está livre, pelo contrário, ela pode ser carregada de processos necropolíticos,${ }^{13}$ como os que aparecem nos mecanismos de controle populacional pelos smartfones: o que agora é usado e "testado em escala" certamente poderá ser herdado como mecanismos para o futuro. ${ }^{14}$ As tecnologias da informação e comunicação são outros aspectos a considerar, sobretudo nos impactos dos algoritmos e da inteligência artificial no aprimoramento do controle, ainda que se possa encontrar neles potenciais incríveis e ainda pouco trabalhados. Saber "quando entrar nele" e "quando e em que condições sair dele ${ }^{\prime \prime 15}$ é decisão que implica um volume maior ou menor de afetados ou de mortes, em consequência. Um é o aspecto biopolítico implicado, outro é o aspecto ético, inclusive considerando o subjetivo, da responsabilidade pessoal e coletiva.

\section{Por uma nova ciência, não neutra}

A neutralidade da ciência reduziu as finalidades humanas e suas necessidades vitais a interesses compatíveis em processos parciais partindo da distinção entre a orientação a valores e a orientação a fatos formalmente estabelecida como parâmetro de toda ciência. Produziu-se um modo de ciência bem funcional ao capitalismo. Assim a ciência não pode se ocupar de questões amplas e globais: não seria possível lidar com necessidades comuns, tão

13 Como, aliás foi questionado por Achile Mbembe, em entrevista à Gaúcha ZH do Rio Grande do Sul publicada com o título "Pandemia democratizou o poder de matar", em 31 de março de 2020.

14 Ver as ponderações de Byung-Chul Han, entre outras, em "Sopa de Wohan" (2020)

15 Jürgen Habermas, em entrevista a Nicolas Truong do Le Monde (11/04/2020) diz que "Com a decisão relativa ao momento apropriado para pôr fim ao confinamento, a proteção da vida, que se impõe não apenas no plano moral, mas também no plano jurídico, podemos nos deparar com, digamos, as lógicas utilitaristas de cálculo”. 
somente com interesses gerais ou interesses comuns, preferências, por serem impossíveis de serem submetidas à dinâmica instrumental da razão meio-fim. Não seria factível submeter à investigação científica às necessidades humanas, melhor lidar com os interesses e preferências (como já sugeria Adam Smith em "A riqueza das nações"). As necessidades são por demais subjetivas para serem escrutinadas pela ciência. A teoria da ação racional só pode lidar com fins específicos, as necessidades são gerais e comuns, nunca específicas. Para ser objetiva, a racionalidade precisa poder fazer o cálculo de eficiência e, para isso, precisa lidar com fins específicos para os quais calcula meios também específicos. Ao fazer isso, institui a eficiência e a competição como valores absolutos que se sobrepõem a todos os demais valores que dialogam com a vida e suas necessidades.

Reduzir a racionalidade científica ao que pode ser submetido ao cálculo meio-fim para viabilizar "objetividade" é incorrer na "falácia abstrativa". É também desconsiderar que a condição de todo fim é tão objetiva quanto qualquer fim específico. Pensar assim requer superar a racionalidade cindida na distinção entre uma racionalidade voltada a valores e outra voltada a fatos. A racionalidade lida com valores, ainda que nem sempre os explicite e, por vezes, os eleja como absolutos sem que assim o admita (é o que faz a racionalidade meio-fim ao eleger a eficiência e a competição como valores absolutos, por exemplo, ainda que não o admita). Uma ciência sem sujeito e somente ocupada por um ator (com papeis e personagens pontuais) é a que pode aspirar a uma objetividade ao modo de neutralidade que tem sido tão cara ao positivismo mortífero e necrófilo, que assim se caracteriza, como ilustra Hinkelammert ${ }^{16}$. A questão está em trabalhar com uma racionalidade fundamental que reconheça e trabalhe com o "sujeito necessitado" e não somente do "ator" e os eventuais papeis que pode representar.

A necrociência se combina e é um bom apoio para a necropolítica e a necroética que vão defender que a morte como ação programada e realizada, de modo que, por isso, "muitos morrerão" com a pandemia e não há muito o que fazer. Aliás, entre morrer de peste e morrer de fome não há muita diferença; vai-se morrer, muitos morrerão, então que morram trabalhando, sendo ela até uma "colaboração" competitivamente até desejável na acumulação capitalista. O que não pode ser questionado, por ser sempre eivado de ideologia são as totalidades mortíferas. Fiquemos com os fins específicos e os meios que os viabilizam. Que a vida pereça, que viva a "objetividade".

\section{Por uma racionalidade ética}


A questão de fundo que se coloca é a possibilidade de uma racionalidade ética na qual caibam as mais diversas e todas as formas de conhecimento, de ciência, de vida. Esta racionalidade ética haverá que emergir da necessidade de superação da racionalidade vitimária ${ }^{17}$ que é exatamente esta racionalidade que admite a morte como parte "naturalizada" (ainda que não seja "natural") e "normalizada" e que trabalha com o"cálculo do suportável".18 Não há suportável possível quando se trata da vida, do sujeito necessitado (que é o humano, mas um humano natural, um humano-natureza). Submeter a ética ao cálculo meio-fim é exatamente eliminá-la do contexto da ciência e autorizar a "ciência dos fatos" a seguir acreditando que está trabalhando sem valores, quando, na verdade, está orientada por valores absolutos como a eficiência e a competição, além de outros.

Problematizar estas questões é abrir-se para possibilidades outras de ciência com ética. Enfim, a possibilidade de uma racionalidade ética se coloca como questão fundamental também neste momento, não como um "post factum" ou "post festum", mas como processo presente e constitutivo da travessia em curso.

Um dos principais desafios que se coloca é a necessidade de "aprender a dignidade da vida". Trata-se de compreender que a vida não "tem" valor, "é" valor. A vida não pode ser relativizada ou condicionada a qualquer outro valor. Nela há uma dignidade própria, que não pode ser ultrapassada, como condição material. A vida é a condição para todas as demais condicionalidades específicas. A fragilidade da vida, que torna a todos os corpos vulneráveis à contaminação do novo coronavírus, sua finitude e sua construção como parte de um amplo processo vital do conjunto do cosmos e particularmente da Mãe Terra, não a coloca em secundidade, pelo contrário, a inserem nesta ampla teia vital. A vida é finalidade omnidimensional de todas as decisões e de todas as ações, não podendo ser posta como mais uma das finalidades disponíveis, exatamente por sua indisponibilidade.

A vida, e suas necessidades, não é um fim para a qual se pode calcular meios eficazes. Ela é condição de todo fim e a possibilidade de ter fins específicos, além de se colocar assim também para todos os meios. E isto é tão objetivo quanto qualquer fim especifico. A vida também não é um direito; é a condição de todo Direito e de todos os direitos, de modo que, em sentido profundo, todos os direitos só fazem sentido para a vida. Todo dinheiro, todo trabalho, toda economia, só fazem sentido se forem para alimentar a vida. Somente em dinâmicas necrófilas é que se poderia esperar outras possibilidades de compreensão.

17 Trabalhamos as características da racionalidade vitimaria e da racionalidade ética em nossa tese (2015) e à luz das contribuições de Enrique Dussel em “Ética da Libertação na idade da globalização e da exclusão” (1998; 2000).

18 Que exige tomar em conta, mas ir muito além dos protocolos biomédicos da OMS e OPAS, entre os quais o que está descrito em: "Orientación ética sobre cuestiones planteadas por la pandemia del nuevo coronavirus (COVID-19)". 
A precaução tem sido invocada como elemento para pensar e agir alternativamente. Afirmada com ênfase a partir das lutas ambientalistas, a precaução se constitui em orientação para a responsabilidade como elemento chave para dirigir a prática ética e científica ${ }^{19}$. No contexto da pandemia, parece estar em suspenso, ainda que seja desejada por quem pensa que qualquer possibilidade de futuro dependeria em muito do modo como se trataria o tema no seu desenvolvimento presente. Por outro lado, as urgências podem ser exatamente portadoras de perspectivas pouco animadoras no sentido de sua efetivação. Há, no entanto, ainda que na urgência, a necessidade de que esta não seja ao modo de comprometer a condição de tudo, que é a vida. Ou, dito de outro modo, nada pode comprometer a vida, por justificativa alguma, e não a vida em abstrato, mas a dignidade de cada uma e de todas as vidas.

\section{E os direitos humanos, em travessia...}

Os organismos de proteção dos direitos humanos publicaram orientaçõe ${ }^{20}$ importantes para atravessar este momento. São fundamentais, mas mais fundamental ainda é entender que estamos no meio de uma travessia.

O grande escritor brasileiro, Guimarães Rosa, em "Grande Sertão, Veredas", de 1956, dizia que, quem fica entretido nos lugares de saída ou da chegada nada vê no meio da travessia. Ele desafia a uma certa "ontologia da realidade presente" aberta a possibilidades! Segundo ele "o real não está na saída nem na chegada: ele se dispõe para a gente é no meio da travessia" (1995, p. 86). $E$, noutra passagem, quem se propõe à travessia é como o que "[...] quer passar um rio a nado, e passa; mas vai dar na outra banda é num ponto muito mais embaixo, bem diverso do em que primeiro se pensou" (1995, p. 43).

Três aspectos ajudam a compreender o significado de travessia: a condição contextual, a condição antropológica e a condição ética. A condição contextual diz que a Covid-19 ataca corpos vulneráveis e mais ainda os mais vulnerabilizados pela desproteção resultante da concentração dos bens comuns e da desigualdade, da pobreza que afastam as maiorias da realização de direitos, condenados que restam "à sorte" do mérito. A condição antropológica diz que os/as humanos/as são finitos e conscientes de sua inconclusão, frágeis ao ambiente natural, mas também abertos/as e em processo de humanização como obra humana cuja vocação é ser mais (o que inclui também

19 Ver nossa tese (2015). Um interessante estudo poderia ser feito no que diz respeito à "heurística do medo" e com este princípio se apresenta no pensamento de Hans Jonas.

20 Ver particularmente do ACNUDH/ONU em "Directrices relativas a la COVID-19" e da CIDH/OEA em "Resolución n. 01/2020: Pandemia y Derechos Humanos en las Américas (Adoptado por la CIDH/OEA el 10 de abril de 2020)". 
o seu inverso, a possibilidade de desumanização pela opressão). A condição ética diz que tornar-se humano é promover a vida como incondicional (vida é valor e condição de todo valor) em processo para sua produção, reprodução e desenvolvimento como vida em abundância (amor à vida) (mas pode também submeter a vida ao "cálculo do suportável" como se fosse possível algum tipo de eficiência ética).

Travessia pode ser simples passagem, passamento, ultrapassamento. Mas esta não é a que nos interessa. A que afirmamos é a que pode ser: a) experiência de processo; b) exercício de paciência; e c) abertura para a busca. Todas estas possibilidades serão realizáveis se a crítica e a reflexão forem mantidas, se o engajamento solidário for incentivado e se a responsabilidade for exercitada...

A proposta de direitos humanos em travessia significa compreender a contingência da travessia. É também compreender que os direitos humanos estão nela. Mas não é abrir mão da universalidade, da interdependência e da indivisibilidade dos direitos humanos; o que também exige não abrir mão das responsabilidades com a realização de todos os direitos humanos com todos/ as e para todos/as.

No fundo, isso será possível se for mantido o desejo do infinito, o desejo do impossível, ${ }^{21}$ que são capazes de ajudar a lidar com a "situação limite" que estamos vivendo para desenhar um "inédito viável"22. Esta é a tarefa pedagógica mais forte a ser levada adiante no contexto em que vivemos. Ainda que a margem que imaginarmos possa ser bem outra daquela a que se chegar, dificilmente se chegará a alguma se não se mantiver a imaginação em ação.

\section{Considerações finais para seguir a conversa...}

O momento exige a mobilização das diversas racionalidades e das diversas sensibilidades humanas, sobretudo aquelas críticas e reflexivas para fazer a travessia, ainda que considerando a grande incerteza que a caracteriza. Não é momento para privilegiar uma ou outra expressão da criatividade humana. Abrir mão da crítica reflexiva poderia comprometer a humanidade senão mais, ao menos tanto quanto qualquer pandemia física.

Por isso, acima de tudo, o momento exige que se recoloque a questão ética e política, junto com a questão epistemológica, de modo a discutir o império da ciência e da tecnologia, ou de uma certa concepção destas formas de saber e de fazer. O que não é aceitável, de modo algum, é o fundamentalismo científico.

21 Ver a grande contribuição sempre atual de Franz Hinkelammert em “Crítica à Razão Utópica” (1984).

22 Como sugeriu Paulo Freire em "Pedagogia do Oprimido" (1975). 
A abertura dialógica interdisciplinar e, talvez, até interseccional entre os diversos saberes e conhecimentos, de modo a recolher ao máximo a experiência acumulada, desperdiçando-a ao mínimo possível, é esforço de cooperação, de ubuntu, o que se coloca como maior desafio neste momento.

\section{Referências}

ACNUDH/ONU. Directrices relativas a la COVID-19. 2020. Disponível em: www. ohchr.org/SP/NewsEvents/Pages/COVID19Guidance.aspx e www.hchr.org. co/files/Covid-9/Directrices_OACNUDH_Covid19_y_DerechosHumanos.pdf. Acesso em: 22 jul. 2020.

ADORNO, Theodor W.; HORKHEIMER, Max. Dialética do esclarecimento. Fragmentos filosóficos. Trad. Guido Antônio de Almeida. 3. ed., Rio de Janeiro: Zahar, 1991.

ALISTAIR, Smouth. É possível, não certo, que vacina contra Covid-19 esteja disponível neste ano, diz desenvolvedora de Oxford. G1 Globo, 21/07/2020. Disponível em: https://g1.globo.com/bemestar/coronavirus/ noticia/2020/07/21/e-possivel-nao-certo-que-vacina-contra-covid-19-estaradisponivel-neste-ano-diz-desenvolvedora-de-oxford.ghtml. Acesso em: 22 jul. 2020.

BACON, Francis. Novum organum. Trad. J. A. Reis de Andrade. São Paulo: Abril Cultural, 1973. Os Pensadores.

BENJAMIN, Walter. Sobre o conceito de história. In: LÖWY, Michael. Aviso de Incêndio: uma leitura das teses "Sobre o Conceito de História". Trad. W.N.C Brandt [Trad. das Teses por Jeanne M. Gagnebin e M. L Müller]. São Paulo: Boitempo, 2005.

CARBONARI, Paulo César. A potencialidade da vítima para ser sujeito ético: construção de uma proposta de ética a partir da condição da vítima. Tese de Doutoramento. PPG Filosofia Unisinos, São Leopoldo, 2015. Disponível em: www.repositorio.jesuita.org.br/handle/UNISINOS/4517. Acesso em: 22 jul. 2020.

CIDH/OEA. Resolución n. 01/2020: Pandemia y Derechos Humanos en las Américas. Adoptado por la CIDH/OEA el 10 de abril de 2020. Disponível em: www.oas.org/es/cidh/decisiones/pdf/Resolucion-1-20-es.pdf. Acesso em: 22 
jul. 2020.

DUSSEL, Enrique D. Ética da libertação na idade da globalização e da exclusão. Trad. Jaime A. Clasen et al. Petrópolis: Vozes, 2000.

FREIRE, Paulo. Pedagogia do oprimido. 2. ed., Rio de Janeiro: Paz e Terra, 1975. GABRIEL, Markus. “O naturalismo é a metafísica mais idiota, o pensamento mais estúpido da história e vai destruir a humanidade". Entrevista para Patricia Fachin, IHU On Line, 13/07/2020. Disponível em: www.ihu.unisinos. br/600862-a-metafisica-naturalista-e-a-raiz-da-autodestruicao-do-ser-humano-entrevista-especial-com-markus-gabriel. Acesso em: 22 jul. 2020.

G1. Mandetta diz que Bolsonaro 'exonerou a ciência' ao demiti-lo. G1 Globo, 20/05/2020. Disponível em: https://g1.globo.com/politica/noticia/2020/04/27/mandetta-diz-que-bolsonaro-exonerou-a-ciencia-ao-demiti-lo.ghtml. Acesso em: 22 jul. 2020.

HABERMAS, Jürgen. Entrevista a Nicolas Truong. Le Monde, 11/04/2020. Trad. Frédéric Joly. No Brasil publicada por Fios do tempo, em 12/04/2020. Disponível em: https://ateliedehumanidades.com/2020/04/12/fios-do-tempo-precisamos-agir-com-o-saber-explicito-de-nosso-nao-saber-entrevista-com-jurgen-habermas/. Acesso em: 22 jul. 2020.

HAN, Byung-Chul. La emergencia viral y el mundo de manana. In: AMADEO, Pablo (Ed.). Sopa de Wuhan. [s.l.]: ASPO (Aislamiento Social Preventivo y Obligatorio). 2020. p. 97-111.

HAWKING, Stephen W. Uma breve história do tempo. Do big bang aos buracos negros. Trad. Maria H. Torres. Rio de Janeiro: Rocco, 2000.

HEISENBERG, W.A. Imagem da natureza na física moderna. Lisboa: Editora do Brasil,1980.

HINKELAMMERT, Franz. El sujeto y la ley: el retorno del sujeto reprimido. Heredia, Costa Rica: EUNA, 2003.

HINKELAMMERT, Franz. Crítica à razão utópica. Trad. Álvaro Cunha. Rev. H. Dalbosco, São Paulo: Paulinas, 1988 [nova tradução de Silvio Salej Higgins. Chapecó: Argos, 2013]. 
MARREIRO, Flávio. Nem o pior ministro da Saúde fez o que Exército está fazendo, desmontando a engrenagem do SUS. El País, 25/06/2020. Disponível em: https://brasil.elpais.com/brasil/2020-06-25/nem-o-pior-ministro-da-saude-fez-o-que-exercito-esta-fazendo-desmontando-a-engrenagem-do-sus. html. Acesso em: 22 jul. 2020.

MBEMBE, Achille. "Pandemia democratizou o poder de matar". Entrevista à Gaúcha ZH. Porto Alegre, 31 de março de 2020. Disponível em: https://gauchazh.clicrbs.com.br/politica/noticia/2020/03/pandemia-democratizou-poder-de-matar-diz-autor-da-teoria-da-necropolitica-ck8fpqew2000e01 ob8utoadx0.html. Acesso em: 22 jul.2020.

MBEMBE, Achille. Direito universal à respiração. Trad. Ana L. Braga. São Paulo: n-1 edições [n 20], 2020. Disponível em: https://n-1 edicoes.org/020. Acesso em: 22 jul. 2020.

MBEMBE, Achille. Crítica da razão negra. 2. ed. Trad. Sebastião Nascimento. São Paulo: n-1 edições, 2018.

MS. Brasil entra em parceria para produção de vacina contra Covid-19, Ministério da Saúde (MS), 27/06/2020. Disponível em: www.saude.gov.br/noticias/ agencia-saude/47132-brasil-entra-em-parceria-para-producao-de-vacinacontra-covid-19. Acesso em: 22 jul. 2020.

OLIVEIRA, Mayara. Na pandemia, ciência e pesquisa são negligenciadas na agenda de Bolsonaro. Metrópoles, 07/06/2020. Disponível em: www.metropoles.com/brasil/politica-brasil/na-pandemia-ciencia-e-pesquisa-sao-negligenciadas-na-agenda-de-bolsonaro, Acesso em: 22/07/2020.

OMS e OPAS. Orientación ética sobre cuestiones planteadas por la pandemia del nuevo coronavirus (COVID-19). 2020. Disponível em: www.paho.org/es/ documentos/orientacion-etica-sobre-cuestiones-planteadas-por-pandemia-nuevo-coronavirus-covid-19. Acesso em: 22 jul. 2020.

PRIGOGINE, llya O Fim das certezas: Tempo, caos e leis da natureza. São Paulo: UNESP, 1996.

ROSA, João Guimarães. Grande sertão: veredas. Rio de Janeiro: Nova Aguilar, 1995. 
SANTOS, Boaventura de Sousa. Para um novo senso comum. A ciência, o direito e a política na transição paradigmática. 6. ed. São Paulo: Cortez, 2007 [Coleção A Crítica da Razão Indolente: contra o desperdício da experiência, v. 1].

SCHLINDWEIN, Manoel. O duro recado da comunidade científica ao ministro da saúde. Revista Veja, 30/04/2020. Disponível em: https://veja.abril.com.br/ blog/radar/o-duro-recado-da-comunidade-cientifica-ao-ministro-da-saude/. Acesso em: 22 jul. 2020.

WEBER, Max. Economia e sociedade. Fundamentos da Sociologia Compreensiva. Trad. Regis Barbosa e Karen E. Barbosa. Brasília: UnB, 1991. v. I.

WEBER, Max. O sentido da "neutralidade axiológica" nas ciências sociais e econômicas. In: Metodologia das Ciências Sociais 2. Trad. Augustin Wernet. Campinas: Unicamp; São Paulo: Cortez, 1995. 
